\title{
Activity Theory Practice in Open and Distance Learning: Implications for Learning Virtually
}

\author{
J. Nyoni \\ Department of Educational Leadership and Management, \\ University of South Africa \\ nyonij@unisa.ac.za
}

Doi:10.5901/mjss.2013.mjss.v4n14p735

\begin{abstract}
Since the advent of modern technology, going viral on virtual learning $(V L)$ in open and distance learning (ODL) is becoming more and more popular among the many institutions of higher learning. This article focuses on the shift from learning virtually $(L V)$ to viral VL which might result in unintended consequences such as the exclusion of prospective postgraduate students and staff. Going viral in this context refers to the introduction and spread of online learning until the institution goes wholly online. Data for this article was collected from 12 Advanced Certificate in Education (ACE) (Leadership and Management) postgraduate Unisa students who received their mediation experiences through LV modalities augmented by the use of short message services (SMSs). The qualitative exploratory case study investigated, analysed and described the views of public school principals in rural Mpumalanga Province. The results showed that the majority of students prefer the modular LV methodology albeit augmented by the use of SMS to facilitate a quicker channel of communication. In this article, we proffer that the university's tuition model for postgraduate programmes should not completely be virtual learning as the process might unintentionally exclude a large number of students who experience burdensome costs and connectivity challenges particularly in rural Africa. But the recommendation is that in order for virtual learning to work, it should be blended with paper-based (hard copy) printed materials as is envisaged by ODL practices.
\end{abstract}

Key words: Open and distance learning (ODL); learning virtually (LV); virtual learning (VL); activity theory

\section{Introduction}

It has been said many a times that education is a basic human right, which is vital to personal, societal development. It is the cornerstone of the well-being of the masses. Education enhances lives; it breaks generational cycles of poverty and disease, and provides the means for sustainable development. Distance learning, among other approaches to education, is an increasingly important aspect of higher education provisioning because it meets the needs of an expanding pool of students who find education necessary for jobs in today's information age. Unlike the industrial era when skills needed were relatively fixed, today education is needed to meet employers' growing demand for continually evolving skills. Distance learning provides a convenient, flexible, manageable alternative for this developing segment of society.

Moore \& Kearsley (1996) defines distance education as "planned learning that normally occurs in a different place from teaching and as a result requires special techniques of course design, special instructional techniques, special methods of communication by electronic and other technology, as well as organizational and administrative arrangements". This definition incorporates all the components of distance education, modifying it from face to face (contact) education with the addition of certain techniques for each component. The term "distance" although a necessity, puts limitations that concern not only technological aspects, but also pedagogic such as course and instruction design. Researchers mostly exploit the technological features of Information and Communication Technologies (ICTs) for the design and development of ODL environments, without paying much attention to and applying theoretical models, pedagogical principles and instructional goals. There are no pedagogic principles that technology serves; rather technology drives the pedagogic principles that are exploited in ODL systems. By the same token, large literatures more often than not like equating online mediation with ODL which is a misnomer as the two are neither similar nor synonymous in any manner. Online is just but one of the teaching and learning mediation tools that can be used in learning virtually (LV) interactivities in ODL. Online learning is a viable way of provisioning distance learning provided the necessary pedagogical and instructional design principles are followed. It is the technologies used in online learning that are tools and require some necessary theoretical and pedagogical direction to achieve viable instruction purposes at a 
distance. Online learning is but one of the mediation tools that are used in ODL for the purposes of facilitating both student and lecturer engagement with learning and teaching experiences.

Virtual learning $(\mathrm{VL})$ and learning virtually (LV) refer to a set of teaching and learning strategies and/or educational methods/tools that can be used to overcome spatial and temporal separation between mediators and students (learners) in ODL. For purposes of this article, we adopt Boynton's (2009 p. 13) description of going viral in epidemiological terms:

...there is no single source from which all persons are "infected." Instead infection is spread through contact: It starts when a few individuals are infected. Each comes in contact with others who are then infected. Each of the infected at time 2 come into contact with additional individuals who are infected. And this continues until the process has run its course.

Based on Boynton's (2009) definition, we use "going viral" to refer to a process of incremental technology adoption in an institution which ultimately leads to all postgraduate programmes being offered wholly online.

ODL pedagogy is moving from a peripheral form of educational approach and mediation to one that is a central pillar in many countries' and institutions' education systems and delivery. The evolution of ICTs has had a positive effect on the development of ODL. Education initiatives globally have struggled to keep track of current educational and technological developments. As a result, many of the countries that have been using distance or correspondence education have continued to employ first generation methodologies (correspondence courses with text-based materials similar to those used in the classroom and delivered through the postal system), while some have introduced second generation methodologies (mainly print-based and characterised by self-instructional design) and third generation methodologies (self-instructional print integrated with audio and video) (Taylor, 2001)). Very few countries appear to have moved to fourth generation methodologies that use interactive ICTs to support course delivery and learning but the demand for appropriately skilled employees in line with the demands of the ever evolving economy has continued to increase (see figure 1). The demand for places in higher education in the world by 2025 will astronomically increase to about 262, 8 million and in Africa alone in will be about 11,6 million (see figure 1). On close analysis, the demand for higher education places as measured from 2000 to 2025 for the identified regions, at least according to the graph shown below, indicates that the figures would have more than doubled.

Figure 1: Graphic feed: growing global demand for higher education (2000-2025)

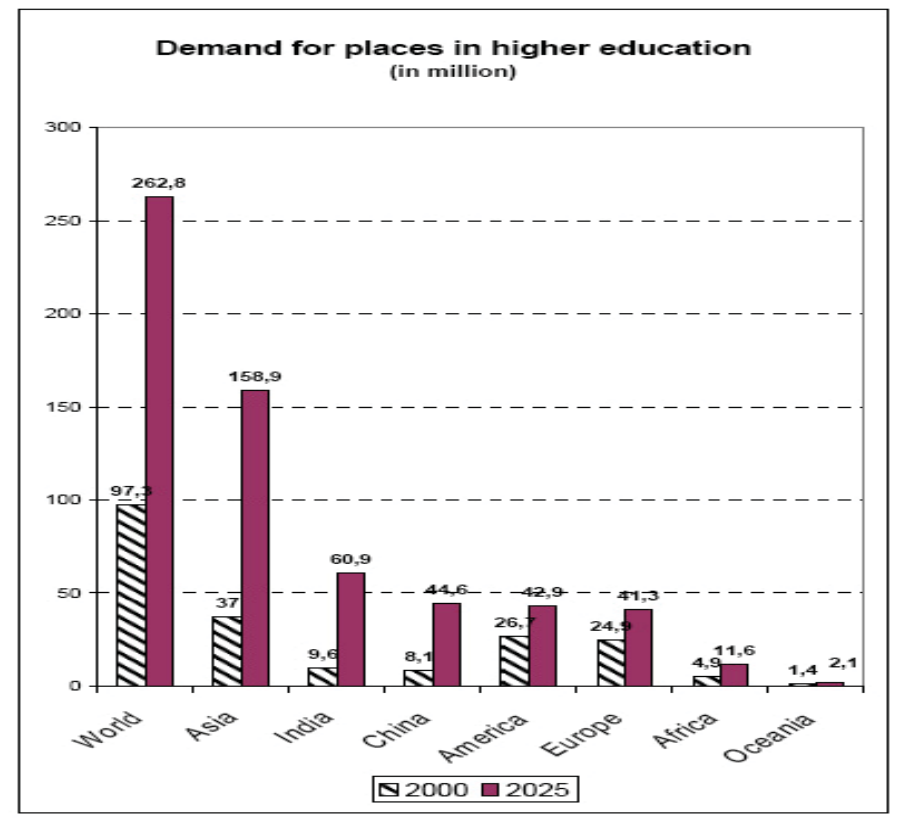

Source: Brandenburg, U., Carr, D., Donauer, S., Berthold, C. (2008) Analysing the Future Market - Target Countries for German HEls, Working paper No. 107, CHE Centre for Higher Education Development, Gütersloh, Germany. 
In South Africa, the final version of the National Plan for Higher Education (NPHE) continues to offer mixed messages about distance education, which stem in part from a lack of clarity about what the plan conceives ODL to be. The lack of clarity on the direction the policy envisions for the future of higher education in South Africa is problematic given the indicated future demand for skilled labour and higher education places reflected in figure 1 above.

In order to meet the demands and expectations of prospective students, institutions of higher education will need to rethink on a continuous basis, possible education methodologies in order to pedagogically adapt their teaching and learning strategies. ICT affordances will make it possible and convenient for students to learn virtually and partake in learning virtually interactive processes.

It is therefore very important, in one hand, to explore the experiences of ODL rural students who are involved with LV (blended learning mediation methods). On the other hand, we have to endeavour to explore their views on how these rural students experience learning virtually tools (LVTs) in the ODL.

\section{Theoretical underpinnings}

Activity theory is designed to enhance learning through the use of ICTs in ODL Higher Education (HE). The theory is reviewed and its extended version, which uses the idea of an activity system to help analyse the use of technology in context, is described. The conceptual framework for representation and analysis of patterns of interaction within collaborative networked learning environments drew upon a range of cross-disciplinary research: psychological models of peer conflict, educational models of "expert-novice" scaffolding, and socio-cultural models of community development, (McAteer, Tolmie, Harris, Chappel, Marsden \& Lally 2002; Chappel, McAteer, Harris \& Marsden, 2002). In situating learning interactivities within ODL educational context and marking that context in terms of potential factors of influence, we acknowledge a debt to activity theory (AT) as grounding the development of our context framework. Engestrom (1987), one of the founding fathers of activity theory (AT), insists that its conceptual tools must be "concretised" according to the specific study of use (Engsestrom 1987; Wells, 2002).

Considering activity theory as a special kind of tool implies that accepting this perspective does not exclude other approaches and does not reject the usefulness of other conceptual schemes - because no tool, no matter how powerful it is, can serve all needs and help solve all problems (Kaptelinin, 1996).

Figure 2: Second generation 'Activity Theory' represented as two intersecting triangles

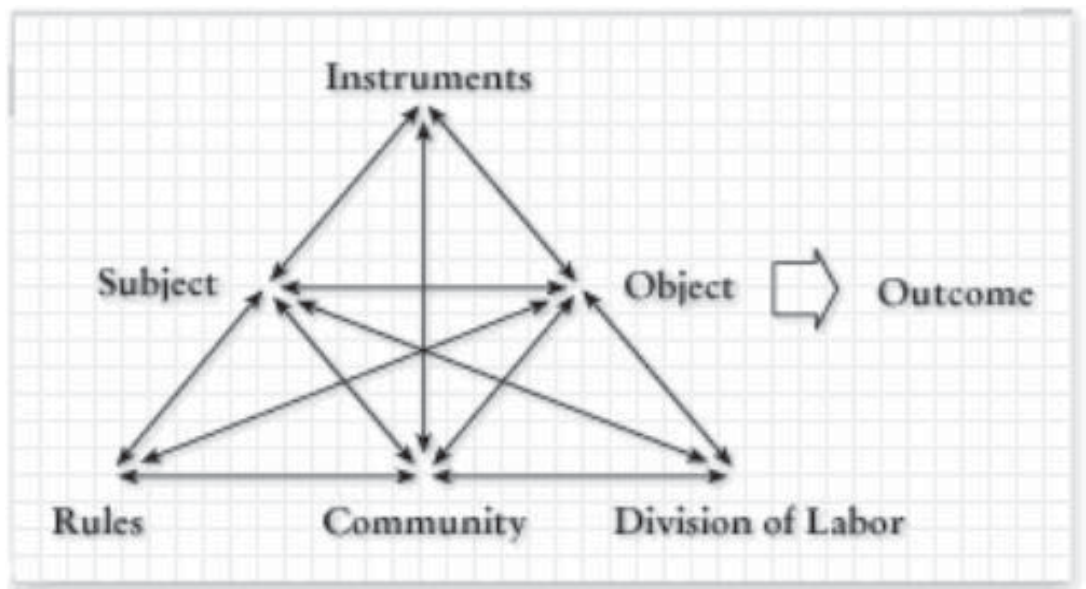

Source: Yrjö Engeström (1987): Learning by expanding

The "activity triangle" representation was originally a Vygotskian model constructed to illuminate relationships between subject and object, mediated through tools. This evolved when Engestrom (1987) added another triangle to represent community, rules and roles and thus represent the more complex social mediation of action, as shown in figure 2. Subsequent representation of activity systems has provoked some criticism and it is important to bear in mind that 
"Although the triangle model may seem somewhat rigid, it is only for the sake of representational simplicity and convenience" (Kuutti, 1996).

The triangle model has been criticised for its inability to cope with multiple perspectives and its unidirectional portrayal of activity. This model is less able to portray reciprocal influences and effects across components, especially necessary when the object of study is a "learning dialogue" (Wells, 2002). Our representation can perhaps more easily deal with these complexities; for example, polymotivation of "subject as collective", that is the class group, is more easily considered when the outcome (hopefully, "learning"!) is situated within the middle of the framework and thus more explicitly mediated by many things. It is also easier to widen out the context framework nodes for different study foci. For example, in many learning situations there is an externally imposed objective (assignment, product, performance) which needs to be taken into account as well as any personal objectives of the individual subject. Our framework is also more flexible in dealing with situations where the objective is less concrete and unidirectional (Russell, 2002). We have taken the "nodes" from Engestrom's (1987) model and set them in a context framework, each for definition to as fine a level of detail as is sensible for any instance of enquiry.

\section{Open and distance learning - what is it?}

For the sake of clarity and common understanding, it is necessary to explain from a South African and sub-Saharan African context the meaning of distance education (DE), open learning (OP), flexible learning and other important educational principles that centre on the concept of $\mathrm{DE}$. Open and distance learning (ODL) refers to approaches to learning that focus on freeing learners from constraints of time and place while offering flexible learning opportunities. For many students, ODL is a way of combining work and family responsibilities with educational opportunities. Distance education (sometimes referred to as "distributed learning" or "distance learning") is any educational mediations in which all or most of the teaching is conducted by someone geographically removed from the learner, with all or most of the communication between teachers and learners being conducted through blended methods such as electronic or print mediums. The "open" nature of distance learning might be formally institutionalised in such policies as open admissions, and freedom of selection of what, when and where to learn. The openness of distance learning is also seen in relatively flexible organisational structures, delivery and communication patterns as well as the use of various technologies to support learning. Open learning $(\mathrm{OL})$ is a philosophy of learning that is based on the principle of flexibility to increase access to and equity in education. An open learning philosophy implies that a provider will try to find a variety of ways to open access to credible learning opportunities to a diverse range of learners. In this context, learners are allowed to determine what they want to learn, how they want to learn, when and where they want to learn and what to do next in terms of career direction.

In an effort to be flexible, providers of open learning opportunities often incorporate the approaches and methodologies associated with ODL and its blended, related delivery strategies. The South African government defines open learning as follows: "Open learning is an approach which combines the principles of learner-centredness, lifelong learning, flexibility of learning provision, the removal of barriers to access learning, the recognition of prior learning, the provision of learner support, the construction of learning programmes in the expectation that learners can succeed, and the maintenance of rigorous quality assurance over the design of learning materials and support systems" (National Department of Education, 1995).

South Africa is able to draw from world-wide experience over several decades in the development of innovative methods of education, including the use of guided self-study, and the appropriate use of a variety of media, which give practical expression to open learning principles (National Department of Education 1995 p. 9).

\section{How are open and distance learning deliverables mediated?}

ODL is delivered using a variety of print and electronic systems either through synchronous communication (learning in which all parties participate at the same time) or through asynchronous communication (learning in which parties participate at different times). The main systems are mediated by correspondence, audio-visual means (television and radio), multimedia (audio and text files), and the internet. Correspondence delivery centres on printed study guides, often accompanied by audio and video components such as compact discs (CDs) or DVDs and slides. Interaction is by letters and other written or printed documents sent through postal systems. Educational television and radio delivery uses various delivery technologies - terrestrial, satellite and cable television and radio - to deliver live or recorded lectures to both individual home-based learners and groups of learners in remote classrooms where face-to-face support might be 
provided. Some systems offer limited audio or video conferencing links back to the lecturer or a moderator at a central point.

Multimedia delivery includes text-, audio-, video- and computer-based materials and usually has face-to-face learner support delivered to both individuals and groups. From this approach, instruction is no longer an individual's work, but the work of teams of specialists, media specialists, information specialists, instructional design specialists and learning specialists. Programmes are prepared for distribution to large numbers of learners usually located across a large geographical area. Internet-based systems refer to those in which multimedia (text-, audio-, video- and computer-based) materials in electronic format are delivered to individuals through computers along with access to databases and electronic libraries. These systems enable teacher-student and student-student one-to-one, one-to-many and many-tomany interactions synchronously or asynchronously through e-mail, computer conferences, bulletin boards, and so forth.

\section{Virtual Learning Environments (VLEs)}

ODL is about more than closing the digital divide, as real and concerning as that is. It's a critical part of closing the human rights divide between those who will grow up literate - with skills, possibilities, and hope - and those who will not. But a learning environment doesn't necessarily have to involve digital technologies in order for it to be considered a virtual learning environment. People over the centuries, especially through the arts, have developed learning settings where individuals need to use their imaginative skills, often including the realm of fantasy, thus creating VLEs. In order to indicate that there are many types of virtual experiences, Weiss (2006) makes an interesting distinction between virtual learning and learning virtually. Weiss states that virtual learning is reserved for digital-/ computer-based learning environments while learning virtually is a much broader term signifying any context that allows for imaginative possibilities. It includes environments utilising a broad array of traditional media and contexts for meaning making.

\section{How is learning virtually (LV) defined in context?}

By revolutionising the way computer teaching and learning mediation processes are conducted in ODL, web conferencing can open the world to both facilitator and students. White board technologies and mini webcams allow for virtual collaboration as well as the ability to see and hear other virtual classmates. Working in a virtual environment also enables students to acquire valuable computer and internet skills, and it strengthens their written and oral communication skills, and opens the door to cross cultural experiences. Most researchers have sought to proffer theoretical perspectives on what and how VLEs can be exploited in order to reach out to ODL students (Weller, 2007; Paulsen, 2003). Very few researchers have attempted to study learning virtually (LV) pedagogy. Weiss (2006) defines learning virtually as, "a much broader term signifying any context that allows for imaginative possibilities. It includes environments utilizing a broad array of traditional media and contexts for meaning making".

A learning environment does not necessarily have to involve digital technologies in order for it to be considered a virtual learning environment! People over the centuries, especially through the arts, have developed learning settings where individuals need to, "use their imagination, often including the realm of fantasy, thus creating VLEs" (Weiss, 2006). Learning virtually can be possible in developing countries where VL mediation is limited due to a variety of circumstances (Bruner, 1986). Learning virtually can be possible with other settings that enable learners to make imaginative interpretations. Interactions with other objects (paintings, prints, photographs, musical and dramatic presentations) and media (radio, movies, television) are but a few of the possibilities for creating virtual texts.

\section{The inclusion of online education in open and distance learning delivery modes}

Technological developments have created new possibilities for distance education. Information and communication technology (ICT) can make it possible to connect people to each other and create interplay between people regardless of time, place, regions, and countries (Guri-Rosenblit, 2009; Miller \& King 2003). For example, Garrison (2009) notes that the development of technology changed how teaching was carried out from the independence in the early selfinstructional correspondence packages to two-way communication (e.g. the emergence of audio conferencing in the late 1970s). Stocks, Mclsaac and Nirmalami Gunawardena (1996) describe how radio during the First World War impacted the delivery systems in education. Since the 1960s, the impetus for developing distance education has been the desire to provide education for all, to enrich people's lives, to drive economic growth in terms of economy of scale, and to spread higher education to all classes (Powell \& Keen 2006). 


\section{Global trends on learning virtually in ODL}

Higher education has expanded remarkably in recent decades. Growth is, by all measures, faster than anticipated. Projections gave 120 million students worldwide by 2020, but that number has already been achieved (Daniel, Kanwar \& Uvalić-Trumbić, 2007). In 2004, 132 million students were enrolled worldwide, up from 68 million in 1991 (Van der Wende, 2008). Average annual growth from 1991 to 2004 was 5.1 per cent. Most of this growth has been in Africa, Asia, Latin America and the Caribbean, the Arab countries, and in Eastern and Central Europe. China and India have doubled their enrolments in the past 10 years alone. In many countries, youth and young adults have driven this increase but in others, such as Canada, New Zealand, and the United Kingdom, a significant number of older adults have also been entering the system (Santiago, Tremblay, Basri and Arnal 2008). In 2006 in Canada, for example, the majority of parttime students (approximately 190,000 of 275,000) were 25 years old or older (Association of Universities and Colleges of Canada 2007).

Given their combined population, for Asia, South America, and Africa to reach a level of post-secondary penetration equal to that of developed countries, they would have to build tens of thousands of traditional universities, each accommodating 40,000 students. While the inevitable growth of universities in the developing world will transform the map of higher education worldwide, new approaches are clearly needed. It is generally acknowledged that open and distance education is a good way of reaching out to large numbers of students.

India accounts for a quarter of the developing world's population and has the third largest higher education system in the world. Approximately 24 per cent of all higher education students in India are enrolled in distance education institutions, specifically in the 13 national and state open universities and the 106 institutions, mostly public, which offer both on campus and correspondence programmes.

\section{Methodological frame}

The qualitative exploratory case study investigated, analysed and described the views of public school principals in rural Mpumalanga Province who were in their second year of the Advanced Certificate in Education, in the Education leadership and Management stream. The study used thematic network that was developed starting from the basic themes and working inwards toward a global theme. Once a collection of basic themes was derived, we then classified them according to the underlying story. The themes were split into three broad stages: (a) the reduction or breakdown of the text; (b) the exploration of the text; and (c) the integration of the exploration. While they all involve interpretation, at each stage a more abstract level of analysis is accomplished.

\section{Steps in analyses employing thematic networks}

\section{ANALYSIS STAGE A: REDUCTION OR BREAKDOWN OF TEXT}

Step 1. Code the material

(a) Devise a coding framework

(b) Dissect text into text segments using the coding framework

\section{Step 2. Identify themes}

(a) Abstract themes from coded text segments

(b) Refine themes

Step 3. Construct thematic networks
(a) Arrange themes
(b) Select basic themes
(c) Rearrange them into organizing themes
(d) Deduce global theme(s)
(e) Illustrate as thematic network(s)
(f) Verify and refine the network(s)

ANALYSIS STAGE B: EXPLORATION OF TEXT

Step 4. Describe and explore thematic networks

(a) Describe the network

(b) Explore the network

Step 5. Summarise thematic networks

Step 6. Interpret patterns 
The study focused on the exploration of views and experiences from predominantly ODL rural ACE students on the use of learning virtually tools in mediation processes. It included 12 ACE Leadership and Management postgraduate students.

The exploratory case study design followed a philosophical assumption of honesty from the interviewees that guided the study, and a strategy of inquiry supporting an interpretative approach to understanding the views, reasons, and experiences of participants in the exploratory study (Flyvbjerg, 2006). Yin (2009) stated that a research design is a critical process that involves the conceptualisation of a problem and the creation of a narrative. Semi-structured interviews were used as they are essential sources of case study information (Yin, 2009). The data collection strategy also included voice recording and non-verbal cues.

\section{Findings, discussion and recommendations}

The rise of ICTs assisted mediation tools does not signal the demise of orthodox teaching and learning methodologies but should be viewed as an augmentation of blended methods designed to accommodate diverse student-centred strategies. Our study confirmed some commonly held beliefs that LV cannot easily be dispensed with in favour of online mediation tools particularly in relation to developing countries in Africa and elsewhere in the world where challenges of connectivity are a common reality. If the quality of student support is to improve as projected from this study, universities must also look at the pedagogical issues in LV. Collaboration, case learning, enhancement of social and lecture presences are likely to be the preferred methods of LV instructors than relying solely on ICTs or online mediated tools. The data presented here also indicate that the continued use of LV methodology will continue to appeal to some of the ODL students over and above the use of online learning and other digital platforms. The following are narrative reports on the views of 12 ACE Leadership and Management postgraduate students who receive their mediation experiences through LV modalities augmented by the use of short message services (SMSs). Five themes emerged through the analysis of data.

\subsection{Effectiveness of mediation tools}

Some instructional strategies are more powerful and effective when used appropriately. Appropriateness criteria must incorporate the availability of relevant ICTs, cost and students' experiences. The majority of students preferred receipt of the materials in hard copy although some materials were posted online in the myUnisa platform where they can access it over a specified period of time. All facilitators need on-going opportunities to learn and practice LV mediation strategies. The facilitators need to make their materials current and relevant to the learners' knowledge and skill application environment. The common thread emanating from the students' responses about the modular material they received reads;

"Just keeps the content relevant to teaching environment and its challenges. It changes and updates every year and is different from year to year. Be plugged in with what's going on in the real world outside your offices/lecture rooms. We need to be equipped to face the real world of teaching today".

As is noted by Smith (2007) that "only by implementing the tools in use by today's students can today's teachers effectively communicate with them, and effectively teach them". This is true due to the fact that many of the current postgraduate students in higher education come with experiences common with earlier traditional learners. This "net generation" has more experience and exposure to information-gathering than older generations, which can be accredited to powerful LV traditional methodologies (Smith, 2007).

\subsection{Quality of feedback}

Quality in these terms is represented by a delivery system that offers equal access to assignments or examinations and which has leeway within the system to allow the student to present the nuances of local practice so that assessment and feedback operate on a level playing field. Students appreciated the fact that they received prompt feedback through SMSs from their lecturers but were not constructive in nature. Some comments indicated; 
"Immediately after assignments have been sent, I receive an SMS and when they are marked I receive an SMS and later I get them through the post". "It is somehow adequate but some assignments are awarded marks and no comments are made".

Written student feedback concerning work towards continuous assessment is at the heart of what students in ODL expect from their distance learning lecturers as has been pointed out by Cole, Coats \& Lentell (1986). Recently developed content standards often ask facilitators, through student mediation tools, to teach students to critical levels than they themselves have had (Cole et al., 1986). Consequently, lecturers must engage in sustained, intellectually rigorous study of what they teach. In addition, those who teach the teachers must model strategies those lecturers are being asked to use in order to give constructive and informative feedback to students.

\subsection{Management of interactive mediation tools}

Among other important beliefs, lecturers must believe that virtually all their students can learn at high levels given appropriate instructional approaches and sufficient time and that their efforts can make a difference in their students' learning. This can be achieved by understanding students' needs and in response identify the most appropriate mediation tools that can keep them motivated. The research question for example sought to understand whether information in the hard copy modular material kept them busy and motivated. The most frequent response was:

\section{"Yes. It motivates a lot because I get more information on how to deal with management and legal issues".}

Dealing effectively with tensions even with hundreds of thousands of students in absentia requires: following very sound organisational principles and good implementation, systematic monitoring of deviations from established procedures and timings, regular review of users' comments and criticisms as well as careful analysis of final results. These management processes help to timeously identify weaknesses which should be attended to thereof in order to avoid frustrations on the part of the students.

\subsection{Support and motivation}

With face-to-face communication, people are able to enjoy the verbal and nonverbal cues that provide instant feedback. Distance education removes these instant cues and can create a cold environment. As a result, McInnerney \& Roberts (2004) note that participant attrition rates are often negative due in large part to the feeling of isolation. Good teachers understand the developmental needs of their students. They also understand the strengths and challenges inherent in the cultures and communities from which those students come. ODL by using a plethora of blended mediation tools, can negate the feeling of isolation by organising face-to-face contact sessions to students in designated convenient venues. The following acknowledgment statement was common among the participants:

"There are two contact sessions per year where we get support and encouragement".

"Only at contact sessions. If there are more sessions, they would give a lecturer more opportunities to work through the module".

Students appreciated the opportunity of meeting with their lecturers let alone their peers. In the contact sessions students enjoyed the cognitive, social and spatial presences.

\subsection{Final discussion remarks}

Policy pronouncements at Unisa) project that; all postgraduate programmes should be offered online. Post 2004, Unisa has been offering ODL courses and programmes using LV blended methods. This interest in distance education at Unisa is related to two factors: For instance, being the African university means the university is responsible for offering higher educational opportunities to all students who want to study and acquire internationally recognised qualifications irrespective of their geographic positions in the African content and the world. Secondly, ICTs have historically been seen as useful tools for ODL (Bramble \& Panda, 2008). 
In order to militate against the possibility of students being denied adequate mediation opportunities to engage with learning experiences, ODL pedagogy encourages the use of a diverse range of blended mediation tools that include learning virtually (LV) to promote a variety of student centred learning experiences. In our exploration process the students indicated that there were five prime factors which constituted effective LVs in ODL and these included receipt of mediation tools, quality feedback, management of interactive mediation tools, cultivation and sustenance of motivation and encouragement and discipline and time management.

Institutions of higher education need to consider whether they are ready to meet growing learner demands in the coming years. First of all, most participants agreed that blended learning would have greater significance in higher education in the future. Although some institutions have already embraced blended learning, many ODL institutions in developing countries such as South Africa need to use LV methodology rather than going viral VL in order to accommodate the needs of the majority prospective students who might not have access to broadband connectivity.

\section{Conclusion}

Activity theory as a special kind of tool implies that accepting VL methodology does not exclude other approaches such as LV (broader mediation of tools) and does not reject the usefulness of other conceptual schemes - "because no tool, no matter how powerful it is, can serve all the needs and help solve all problems" (Kaptelinin, 1996). Credible ODL systems must have means of establishing an individual link with each member of their universe of users. This means that each student is identified as a specific person, to whom correspondence is addressed, assignments are sent, marks are attributed and whose questions receive timely answers. In the case of formal programmes, it is the individual student whose learning achievement is assessed and to whom a certificate, diploma or degree may eventually be awarded. Within the broader LV blended mediation tools, universities need to craft tuition models in line with the needs of the students and accessibility of the learning experiences.

\section{References}

Blin, F. \& Munro, M. (2008). Why Hasn't Technology Interrupted Academics' Teaching Practices? Understanding Resistance to Change Through the Lens of Activity Theory. Computers \& Education, 50 (2), 475-490.

Boynton, B. (2009). Going viral - The dynamics of attention. A paper presented at The Journal of Information Technology and Politics Annual Conference,4/1/2009; 11-38.

Bramble, WJ. \& Panda, S. (2008). Organizational and cost structures for distance and online learning. In W.J. Bramble \& S. Panda (Eds.), Economics of distance and online learning. Theory, practice, and research, (pp. 1-12). Routledge: New York.

Chappel, H., McAteer, E., Harris, R.A. \& Marsden, S. (2002). Fast Coding of On-Line Learning Behaviours using an 'Elements' Approach. Proceedings of Networked Learning 2002. University of Sheffield. UK.

Cole, S., Coats, M. \& Lentell, H. (1986). Towards good teaching by correspondence. Open Learning 1(1): 59-63.

Daniel, J., Kanwar, A. \& Uvalić-Trumbić, S. (2007). "Mass Tertiary Education in the

Developing World: Distant Prospect or Distinct Possibility?" Commonwealth of Learning. http://www.col.org/colweb/site/pid/4605. Accessed on [22 August 2012].

Donnelly, R. \& O'Rourke, K.C. (2007). What Now? Evaluating eLearning CPD Practice in Irish Third-Level Education. Journal of Further and Higher Education, 31(1), 31-40.

Engestrom, Y. (1987). Learning by expanding: An activity-theoretical approach to developmental research. Helsinki, Orienta-Konsultit.

Kaptelinin, V. (1996). Computer-Mediated Activity: Functional Organs in Social and Development Contexts. Context and Consciousness: Activity Theory and Human-Computer Interaction. ed B. A. Nardi. Cambridge, MA, The MIT Press: 45-68.

Kuutti, K. (1996). Activity Theory as a Potential Framework for Human-Computer Interaction Research. Context and Consciousness: Activity Theory and Human-Computer Interaction. B. A. Nardi. Cambridge, MA, The MIT Press: 17-44.

McAteer, E., Tolmie, A., Harris, R.A., Chappel, H., Marsden, S. \& Lally, V. (2002). Characterising On-Line Learning Environments. Proceedings of Networked Learning 2002, . University of Sheffield. UK.

McInnerney, J.M., \& Roberts, T. S. (2004). Online learning: social interaction and the creation of a sense of community. Educational Technology and Society, 7 (3), 73-81. Retrieved from http://www.ifets.info/journals/7 3/8.pdf. Accessed on [02 June 2012].

Mclsaac, S.M. \& Gunawardena, N.C. (1996). Distance Education. In David H. Jonassen (ed.), Handbook of Research for Educational Communications and Technology. New York: Macmillan.

Moore, M. \& Kearsley, G. (1996). Distance Education: a systems view. Thomson: Wadsworth Publishing.

Morey, A. I. (2004). Globalization and the emergence of for-profit higher education. In Higher Education, 48, (pp. 131-150).

Paulsen, M.F. (2003). Online Education and Learning Management Systems - Global ELearning in a Scandinavian Perspective, Oslo: NKI Forlaget.

Russell, D. (2002). Looking beyond the interface: activity theory and distributed learning. In Lea, M \& Nicoll, K. (eds) Distributed Learning: social and cultural approaches to practice. 
Santiago, P., Tremblay, K., Basri, E. \& Arnal, E. (2008). Tertiary Education for the

Knowledge Society: OECD Thematic Review of Tertiary Education: Synthesis Report. Vol. 1.Paris: OECD Publishing.

Smith, C. (2007). When in Rome: Teaching 21st century students using 21st century tools. Retrieved from:http://students.ed.uiuc.edu/arosu2//dealHighSchool/21stcenturytools.pdf\#page=3. Accessed on [20 March 2012].

Taylor, J.C. (2001). Fifth generation distance education. Higher Education Series, Report

no. 40. Higher Education Division, Australia.

Trends in Higher Education. (2007). Volume 1 - Enrolment. Ottawa: Association of Universities and Colleges of Canada. http://www.aucc.ca/pdf/english/publications/trends 2007 vol1_e.pdf.

Van der Wende, M. (2008). "Where do we go from here? Tertiary Education in a Global World: Institutional Views." Presentation to the OECD Conference on Tertiary Education for the Knowledge society, Lisbon, Portugal, April 3-4.

Vygotsky, L. S. (1978). Mind in Society: The Development of Higher Psychological Processes. Cambridge, MA, Harvard University Press.

Weller, M. (2007). Virtual Learning Environments: Using, choosing and developing your VLE, London: Routledge.

Wells, G. (2002). "The Role of Dialogue in Activity Theory." Mind, Culture and Activity 9(1): pp. 43-66. 